\title{
Antioxidants properties of Murraya koenigii: a comparative study of three different extraction methods
}

\author{
${ }^{1}$ Parithy, M.T., ${ }^{1}$ Mohd Zin, Z., ${ }^{2}$ Hasmadi, M., ${ }^{3,4}$ Rusli, N.D., ${ }^{5}$ Smedley, K.L. and \\ ${ }^{1, *}$ Zainol, M.K. \\ ${ }^{1}$ Faculty of Fisheries and Food Sciences, Universiti Malaysia Terengganu, 21030, Kuala Nerus, \\ Terengganu, Malaysia \\ ${ }^{2}$ Faculty of Food Science and Nutrition, Universiti Malaysia Sabah, 88400 Kota Kinabalu, Sabah, \\ Malaysia \\ ${ }^{3}$ Faculty of Agro Based Industry, Universiti Malaysia Kelantan, Jeli, Kelantan, Malaysia \\ ${ }^{4}$ Institute of Food Security and Sustainable Agriculture, Universiti Malaysia Kelantan, Jeli, Kelantan, \\ Malaysia \\ ${ }^{5}$ Stratford School, Stratford-upon-Avon, Warwickshire, CV37 9DH, United Kingdom
}

Article history:

Received: 29 June 2020

Received in revised form: 23

July 2020

Accepted: 16 August 2020

Available Online: 14 October 2020

\section{Keywords:}

Murayya koenigii leaves,

Solvent assisted extraction,

Microwave assisted

extraction,

Ultrasonic assisted extraction, Antioxidant activity

\section{DOI:}

https://doi.org/10.26656/fr.2017.5(1).307

\begin{abstract}
Nutraceutical and pharmaceutical industries have been increasingly engaged in finding natural alternatives compounds as potential antioxidants. The use of phytochemicals is introduced as a good source of natural antioxidants. Murayya koenigii leaves, commonly used in cooking and traditional medicines have been examined for their remarkable antioxidant potential, yet still, it remains an understudied herb. Therefore, this study aimed to determine the antioxidant properties and flavonoids profile in M. koenigii leaves extracted using; solvent assisted extraction (SAE), microwave assisted extraction (MAE) and ultrasonic assisted extraction (UAE). The antioxidant properties of M. koenigii were analysed qualitatively and quantitatively using high performance liquid chromatography (HPLC). M. koenigii leaves extracted using the UAE method have responded strongly towards a 2, 2-diphenyl -2-picryl-hydrazyl DPPH assay with the highest inhibition (\%) of $78.00 \pm 1.00$. Using the ferric thiocyanate (FTC) and thiobarbituric acid (TBA) method assays, the M. koenigii leaves with the lowest absorbance were assigned as a sample with the highest antioxidant activity. The $M$. koenigii leaves extracted using UAE had the lowest absorbance with $0.01 \pm 0.00$. In the TPC assay, the MAE method showed the highest total phenolic content $(120.60 \pm 14.81 \mathrm{mg}$ GAE/g sample). The TFC assay demonstrated that MAE methods have the highest total phenolic content $(93.38 \pm 4.33 \mathrm{mg}$ QE/g sample. The M. koenigii leaves extracted by MAE showed the highest gallic acid, catechin, epigallocatechin gallate, rutin and kaempferol concentration $(\mathrm{mg} / \mathrm{L})$. M. koenigii leaves subjected to SAE extraction has the highest concentration of p-coumaric acid, myricetin and quercetin $(\mathrm{mg} / \mathrm{L})$. This study found that $M$. koenigii leaves extracted using UAE exhibited better antioxidant activities than that of MAE and SAE. These useful findings have managed to narrow the knowledge gap regarding the effects of different extraction methods on the antioxidant property of M. koenigii.
\end{abstract}

\section{Introduction}

In recent times, medicinal plants are on a rave due to their variant physicochemical properties. These natural products have been shown to have antioxidant properties. They are capable of scavenging free superoxide radicals, thus providing anti-ageing benefits as well as reducing the risk of cancer (Ghasemzadeh et al., 2014). A significant role of dietary phytochemicals human health is mainly to minimize oxidative damage to living cells by deactivating reactive oxygen species (ROS), the byproducts produced during normal cell aerobic respiration (Dharmaraja, 2017). Many studies have been carried out on many local herbs in Malaysia; however, there are still some other herbs such as M. koenigii leaves that remain unexplored in depth and more explorations are needed (Azizah et al., 2014). 
The leaves of Murraya koenigii have been widely used in Indian cookery for centuries and have a versatile role to play in traditional medicine (Jain et al., 2012). The M. koenigii leaves are notable for their antitumor, antioxidant, anti-inflammatory, anti-hyperglycemic, and hypoglycemic properties (Dineshkumar et al., 2010). The leaves have a slightly pungent, bitter and weakly acidic taste. They also retain their flavour and other qualities even after drying (Sinha et al., 2012). M. koenigii leaves are generously credited with tonic and stomachic properties. The bark and roots are used as a stimulant and topically to cure eruptions and bites of poisonous animals (Singh et al., 2014). The fresh leaves, dried leaf powder, and essential oils are widely used for flavouring soups, curries, fish and meat dishes, eggbased dishes, traditional curry powder blends, seasoning and other ready to use food preparations (Jain et al., 2012). Traditionally, M. koenigii leaves are boiled with coconut oil until they are reduced to a blanked residue which is then used as an excellent hair tonic for retaining natural hair tone and stimulating hair growth.

In the nutraceutical industry, the extraction process is an important step for the isolation of phytochemicals from herbs and spices (Bak et al., 2012). However, there are some disadvantages with the use of certain types of extraction method such as environmental pollution, lower yields, loss of reactivity, and others. Conventional solvent extraction attracts a higher cost, requires a longer time and is inefficient (Luque-Garcia and Luque de Castro, 2003), therefore alternative extraction needs to be explored to reduce extraction time, reduce solvent consumption, increase extraction yield and improve extract quality. This problem could be hindered by the use of an efficient extraction technique to preserve the beneficial properties of the extract. A comparison with other extraction techniques to obtain beneficial compounds proved to be crucial and important (MedinaTorres et al., 2017). Ultrasound-assisted extraction (UAE) and microwave-assisted extraction (MAE) are recommended for the extraction of analytes from different matrices. The advantages of UAE and MAE are low equipment cost, low energy requirements, reduced solvent quantity and/or time consumption (JacotetNavarro et al., 2016). Therefore, the purpose of this study was to determine the antioxidant properties and flavonoid content in $M$. koenigii leaves extracted using different extraction procedures namely, solvent assisted extraction SAE), microwave assisted extraction (MAE) and ultrasonic assisted extraction (UAE).

\section{Materials and methods}

All samples were dried using the oven drying method (AOAC, 2007) prior to all extraction techniques. The samples were then ground and sieved (10-20 mm size) (Waring Commercial, Torrington. CT, U.S.A) and kept in a dark bottle, stored at $5^{\circ} \mathrm{C}$ until further analysis.

\subsection{Solvent assisted extraction}

Solvent assisted extraction was conducted using $60 \%$ ethanol using a modified method suggested by Zainol et al. (2003). Approximately $10 \mathrm{~g}$ of the finely ground curry leaf powder was added with $100 \mathrm{~mL}$ of $60 \%$ ethanol and left to stand for $1 \mathrm{hr}$. The solvent was then removed leaving the residue for the second extraction. The solvent was filtered using Whatman No. 4 filter paper using a vacuum pump. Post filtration the filtrate was then concentrated using a rotary evaporator (Buchi, Switzerland).

\subsection{Microwave assisted extraction}

Microwave assisted extraction was conducted using a modified method suggested by Dahmoune et al. (2015). The solution was prepared according to a $28: 1$ solvent to solid ratio, where $10.7 \mathrm{~g}$ of dried curry leaf powder was mixed with $300 \mathrm{~mL}$ of $60 \%$ ethanol. The solution was then irradiated for 3 min using a microwave set to $300 \mathrm{~W}$ (Samsung, Korea).

\subsection{Ultrasonic assisted extraction}

Ultrasonic assisted extraction was conducted using a modified method suggested by Zainol et al. (2018). A total of $38 \mathrm{~g}$ powdered $M$. koenigii leaves were mixed with $60 \%$ ethanol. The mixture was submerged in an ultrasonic cleaner bath (Buchi, Switzerland) and extracted for $30 \mathrm{~min}$. The extracted samples were then centrifuged at $700 \mathrm{rpm}$ at $4^{\circ} \mathrm{C}$ for 10 mins. Ethanol was then removed from the extract using a rotary evaporator and the resulting extract was placed in a bottle in the chiller for the next analysis.

\subsection{Determination of antioxidant properties}

\subsubsection{2, 2 -diphenyl -2-picryl-hydrazyl (DPPH) method}

The capacity of trapping of free radical DPPH was evaluated according to the method described by Zainol et al. (2018) with slight modification. A $6.1 \times 10^{-5} \mathrm{M}$ solution of DPPH was prepared in ethanol. Then, $75 \mu \mathrm{L}$ of the diluted extract was added to $3 \mathrm{~mL}$ of the DPPH solution. The absorbance was taken at $515 \mathrm{~nm}$ using methanol with DPPH as the negative control whilst quercetin was the positive control after letting it stabilise for $1 \mathrm{hr}$. All operations or conducted in dark or dim light. The inhibition percentage (IP) of the DPPH by the extract was calculated according to the formula: 


\section{$\mathrm{IP}=[(\mathrm{A} 0 \mathrm{~min}-\mathrm{A} 60 \mathrm{~min}) / \mathrm{A} 0 \mathrm{~min}] \times 100$}

A0 min is the absorbance of the blank at $\mathrm{t}=0 \mathrm{~min}$, and $60 \mathrm{mins}$ is the absorbance of samples at $60 \mathrm{mins}$. The result was expressed as $\mu \mathrm{mol}$ Trolox equivalent (TE) per gram of sample on a dry basis, through a doseresponse curve for Trolox $(0-350 \mu \mathrm{M})$.

\subsubsection{Ferric thiocyanate (FTC) method}

The samples were analysed using methods suggested by Zainol et al. (2003). The adjusted $1 \mathrm{mg} / \mathrm{mL}$ of sample was dissolved in $4 \mathrm{~mL}$ of absolute ethanol (99.5\%), added with $4.1 \mathrm{~mL}$ of $2.52 \%$ linolenic acid in absolute ethanol. Eight millilitres $\mathrm{mL}$ of $0.05 \mathrm{M}$ phosphate buffer (pH7) were mixed with $3.9 \mathrm{~mL}$ of distilled water and kept in a screw cap bottle and placed in a water bath shaker at $40^{\circ} \mathrm{C}$. Approximately $0.1 \mathrm{~mL}$ of samples were added to $9.7 \mathrm{~mL}$ of $75 \%$ ethanol and $0.1 \mathrm{~mL}$ of $30 \%$ ammonium thiocyanate finally by $0.1 \mathrm{~mL}$ of $0.02 \mathrm{M}$ ferrous chloride added in 3.5\% Hydrochloric acid into the reaction mixture. The absorbance of the resulting red -blood colour was measured after 3 mins at $500 \mathrm{~nm}$ every $24 \mathrm{hrs}$ until the day the absorbance of the control reached the maximum value.

\subsubsection{Thiobarbituric acid (TBA) method}

The samples were analysed using methods suggested by Malik et al. (2017). An aliquot (1 mL) of sample solution obtained by the FTC method was added to $2 \mathrm{~mL}$ of $20 \%$ thrichloroacetric acid and $2 \mathrm{~mL}$ of $0.67 \% 2$ thiobarbituric acid. The mixture was placed in boiling water at $100^{\circ} \mathrm{C}$ for 10 mins. Next, the mixture was cooled and then centrifuged at $300 \mathrm{rpm}$ for 20 mins. The absorbance of the supernatant was measured at $552 \mathrm{~nm}$.

\subsubsection{Determination of total phenolic content (TPC)}

The total phenolic compounds were determined using Folin-Ciocalteu reagent according to the colourimetric method described by $\mathrm{Ng}$ et al. (2020). An aliquot $(1 \mathrm{~mL})$ of every sample was diluted into $50 \mathrm{~mL}$ of stock solution. Approximately $1 \mathrm{~mL}$ from the stock solution was added to $17.9 \mathrm{~mL}$ of distilled water in 0.5 $\mathrm{mL}$ of Folin-Ciocalteu reagent and left to stand for 1 min. Then, $1.5 \mathrm{~mL}$ of $20 \%$ sodium carbonate was added to the mixture. The sample prepared was then left at room temperature for $2 \mathrm{hrs}$ in the dark. The absorbance value was taken at $765 \mathrm{~nm}$, resulting in $\mathrm{mg}$ GAE per gram of sample extract (mg GAE/g) expressed as gallic acid equivalent.

\subsubsection{Determination of total flavonoid content (TFC)}

Approximately $50 \mathrm{mg}$ of sample was mixed with 1.5 $\mathrm{mL}$ methanol, $0.1 \mathrm{~mL} 10 \%$ aluminium chloride, $0.1 \mathrm{~mL}$
$1 \mathrm{M}$ potassium acetate and $2.8 \mathrm{~mL}$ distilled water. The mixture was then incubated at room temperature for 30 mins. The absorbance of the reaction mixture was taken at $415 \mathrm{~nm}$. The result was expressed as $\mathrm{mg}$ of quercetin equivalent $(\mathrm{QE})$ per gram of sample extract $(\mathrm{MG} \mathrm{QE} / \mathrm{G})$ as mg quercetin equivalent $(\mathrm{QE}) / \mathrm{g}$ of dried plant material (Chong et al., 2018).

\subsubsection{Determination of individual flavonoid content using HPLC}

All samples were refluxed in $6 \mathrm{M} \mathrm{HCl}$ at $90^{\circ} \mathrm{C}$ for 2 hrs with $60 \%(\mathrm{v} / \mathrm{v})$ aqueous methanol extracted prior to the HPLC analysis (Mohd Zainol et al., 2009). HPLC analysis was performed using an Analytical High Performance Liquid Chromatography (HPLC) (Shimadzu, Japan) with a 4 solvent delivery system quaternary pump (LPG 3400 SD) including a diode array detector (DAD 3000) with $5 \mathrm{~cm}$ flow cell, a manual sample injection valve equipped with a $20 \mu \mathrm{L}$ loop and Chromeleon 6.8 system manager as the data processor. A total of $20 \mathrm{~mL}$ of sample were injected into the HPLC system for every analysis. One percent (V/V) aqueous acetic acid solution and acetonitrile were used as the gradient mobile phase. The flow rate was fixed at 0.7 $\mathrm{mL} / \mathrm{min}$, while the column oven was set at $28^{\circ} \mathrm{C}$. The composition of the mobile phase was back to the initial condition (solvent B: solvent A: 10: 90) in 31 mins and allowed to run for another 5 mins before the injection of the next sample. HPLC chromatograms were detected using a photodiode array UV detector at $270 \mathrm{~nm}$. Each compound was identified by its retention time and by spiking with standards under the same conditions (Seal, 2016).

\subsection{Statistical analysis}

The data obtained were subjected to one-way analysis of variance (ANOVA). The mean comparisons from triplicate analysis were carried out using Fisher's Least Significant Difference (LSD) test (Mamat et al., 2018). Statistical analysis was performed using SPSS software 2004.

\section{Results and discussion}

3.1 Extraction yield from solvent assisted extraction, microwave assisted extraction and ultrasonic assisted extraction

Table 1 shows the extraction yield (\%) of three different extraction methods. The extraction yield of solvent assisted extraction (SAE) showed no significant difference compared to the extraction yield of ultrasonic assisted extraction (UAE) and microwave assisted extraction (MAE). 
Table 1. Total phenolic content, total flavonoid content, ABTS inhibition and DPPH inhibition of the SCG extracted using different extraction methods of M. koenigii leaves

\begin{tabular}{lccccccc}
\hline & Control & SAE & MAE & UAE & BHT & Vit C & $\alpha-$ Tocopherol \\
\hline Extraction yield (\%) & - & $1.47 \pm 0.04^{\mathrm{b}}$ & $1.60 \pm 0.01^{\mathrm{ab}}$ & $1.70 \pm 0.01^{\mathrm{a}}$ & - & - & - \\
DPPH (\%) & $5.20 \pm 0.62^{\mathrm{c}}$ & $63.67 \pm 3.22^{\mathrm{b}}$ & $75.33 \pm 1.53^{\mathrm{ab}}$ & $78.00 \pm 1.00^{\mathrm{ab}}$ & $88.67 \pm 1.16^{\mathrm{a}}$ & $80.38 \pm 3.88^{\mathrm{ab}}$ & $79.32 \pm 3.88^{\mathrm{ab}}$ \\
FTC (Abs) & $0.6 \pm 0.02^{\mathrm{a}}$ & $0.2 \pm 0.01^{\mathrm{b}}$ & $0.16 \pm 0.02^{\mathrm{b}}$ & $0.13 \pm 0.02^{\mathrm{b}}$ & $0.11 \pm 0.02^{\mathrm{b}}$ & $0.13 \pm 0.01^{\mathrm{b}}$ & $0.14 \pm 0.01^{\mathrm{b}}$ \\
TBA (Abs) & $0.95 \pm 0.02$ & $0.34 \pm 0.02^{\mathrm{a}}$ & $0.27 \pm 0.03^{\mathrm{b}}$ & $0.25 \pm 0.01^{\mathrm{b}}$ & $0.16 \pm 0.01^{\mathrm{c}}$ & $0.21 \pm 0.01^{\mathrm{b}}$ & $0.23 \pm 0.01^{\mathrm{b}}$ \\
TPC (mg GAE/g) & - & $58.48 \pm 5.46^{\mathrm{b}}$ & $120.60 \pm 14.81^{\mathrm{a}}$ & $88.79 \pm 4.48^{\mathrm{b}}$ & - & - & - \\
TFC (mg QAE/g) & - & $27.97 \pm 7.12^{\mathrm{c}}$ & $85.23 \pm 2.35^{\mathrm{a}}$ & $66.45 \pm 5.92^{\mathrm{b}}$ & - & - & - \\
\hline
\end{tabular}

Solvent-assisted $=$ SAE, Microwave assisted $=$ MAE, Ultrasonic assisted $=$ UAE. Values represent the mean \pm standard deviation. Values with the same letter superscript are not significantly different $(\mathrm{P}<0.05)$ between samples within rows.

The increasing trend of the extraction yield can be expressed in such a manner where the extraction yield of $\operatorname{UAE}(1.70 \pm 0.10 \%)>\operatorname{MAE}(1.60 \pm 0.01 \%)>\mathrm{SAE}$ $(1.47 \pm 0.04 \%)$. Tiwari (2015) stated that UAE is based on the concept of acoustic cavitation capable of damaging the cell wall of the plant matrix and thus favouring the release of bioactive compounds. This method can be used to extract a wide variety of phytochemicals such as phenolic compounds, indicating that it is the best technique for achieving higher yields. The exceptional capability of the acoustic cavitation to damage the cell wall in ultrasonic assisted extraction (UAE) encourages the release of more phytochemicals, thus increasing the extraction yield in this particular extraction method (Ledesma-Escobar et al., 2015).

\subsection{2, 2 -diphenyl-2-picryl-hydrazyl (DPPH) method}

Table 1 also shows that there was no significant difference between MAE and UAE extracts of $M$. koenigii leaves, $\alpha$-tocopherol and vitamin $C$. The data show that $M$. koenigii leaves subjected to the UAE method reacted strongly with the DPPH assay $(78.00 \pm 1.00 \%)$ followed by the MAE $(75.33 \pm 1.53 \%)$ and the SAE (63.67 $\pm 3.22 \%)$. This can further illustrate the radical scavenging properties of the curry leaf extracts obtained by different methods, where UAE had the highest radical scavenging properties followed by MAE and SAE, as they show higher inhibition (\%) against oxidation. Similarly, strong radical scavenging properties of the UAE method have been demonstrated by the Bouaoudia-Madi et al. (2019) pericarp study of Myrtus communis, where the results show that the UAE extract showed higher DPPH Scavenging capability compared to the SAE and MAE extracts.

\subsection{Ferric thiocyanate method (FTC)}

The ferric thiocyanate (FTC) value of the UAE extract did not show a significant difference compared to butylated hydroxytoluene (BHT), Vitamin $\mathrm{C}$ and $\alpha$ Tocopherol (Table 1). This could indicate that the UAE method extracts reacted strongly to the FTC assay in addition to the DPPH assay. As the lowest absorbance reading on the fourth day of incubation dictates the highest antioxidant quality. UAE methods have been shown to preserve more of the antioxidant quality of $M$. koenigii leaves followed by MAE and SAE methods. The antioxidant quality demonstrated by the samples mimics a number of studies previously conducted. According to Jun et al. (2011), the crude extracts of green tea from the UAE method showed a high radical scavenging capability followed by MAE and SAE. The FTC assay also agrees with previous antioxidant quality patterns demonstrated by the UAE DPPH assay antioxidant quality is the highest compared to MAE and SAE.

\subsection{Thiobarbituric Acid (TBA) method}

The MAE extracts showed the lowest absorbance, indicating that they had the highest antioxidant quality compared to the SAE and UAE methods in the TBA assay (Table 1). Dahmoune et al. (2015) reported that citrus lemon extracts produced using MAE had higher lipid peroxidation compared to SAE and UAE extracts. This explains why MAE peroxidation is lower compared to SAE and UAE methods. Ince et al. (2012) also explained that MAE performed better due to better inhibition of lipid peroxidation by better antioxidant activity against hydroperoxide and free radical formation.

\subsection{Total phenolic content (TPC) method.}

M. koenigii leaves extracted using the MAE method showed the highest total phenolic content (TPC) (120.60 $\pm 14.81 \mathrm{mg}$ GAE/g sample), followed by UAE (88.79 $\pm 4.48 \mathrm{mg} \mathrm{GAE} / \mathrm{g}$ sample) and SAE (58.48 \pm 5.46 mg GAE/g sample). Compared to previous assays, it can be observed that the antioxidant activity of the UAE method in TPC was not as favourable as in previous analyses such as DPPH and FTC assays. This could be due to the high frequency in the UAE that could easily degrade the TPC. Degradation of flavonoids and polyphenol compounds is possible at high frequencies in the UAE (Jahromi, 2019). Routray and Orsat (2012) also reported that for total phenolic extraction, microwave 
applications were observed to have a much higher overall phenolic output than sonication-based extraction.

\subsection{Total flavonoid content (TFC) method.}

Table 1 shows that there is a significant difference between the total flavonoid content (TFC) of $M$. koenigii leaves of three different MAE, UAE and SAE extracts. A similar trend was observed in the TPC analysis. However, the total flavonoid content of $M$. koenigii leaves showed a better significant difference compared to the TPC of $M$. koenigii leaves. The data suggest that $M$. koenigii leaves respond better to oxidation induced by aluminium flavonoid complexes. The total flavonoid content of $M$. koenigii leaves extracted by MAE was also found to be the highest in comparison to UAE and SAE. Analogous results have also been established by Nouha et al. (2017) on Maltese orange peel, where the method with the highest total phenol and flavonoid content is microwave-assisted extraction followed by ultrasoundassisted extraction, conventional solvent extraction.

\subsection{Determination of individual flavonoids using HPLC analysis.}

Figure 1 shows the HPLC chromatogram which verifies the presence of the designated standard flavonoid used in this study, identified by its retention time, while Figure 2 shows the HPLC chromatogram confirming the presence of individual flavonoids in the sample undergoing different extraction treatments, in line with the flavonoid standards shown in Figure 1. The results show that rutin, myricetin, kaempferol, gallic acid, catechin, epigallocatechin gallate, quercetin and pcoumaric acid were present after all types of extractions. These figures indicate the presence of the compounds tested confirming that the HPLC technique used was suitable for the detection, identification and measurement of the availability of flavonoids (Moniruzzaman et al., 2014).

Table 2 shows the flavonoid content in all three samples of $M$. koenigii leaves from three different extraction methods (SAE, MAE and UAE) determined using an HPLC analysis. All samples analysed showed the presence of catechin, epigallocatechin gallate, quercetin, gallic acid, myricetin, kaempferol, rutin and pcoumaric acid (Figure 2). The previous study on $M$. koenigii leaves by Sepahpour et al. (2018) indicated that the $80 \%$ t ethanol extraction yielded $0.9,5.4,2.4$ and 1.4 $\mathrm{mg} / \mathrm{g}$ freeze- crude extract of rutin, quercetin-3-glucoside myricetin and quercetin. It is interesting to note that the different extraction techniques used in the study affected the individual flavonoids differently. Results of the study also found that M. koenigii leaves extracted by MAE had the highest concentration of total individual flavonoids, while SAE showed the lowest concentration of total individual flavonoids between samples. Catechin was found to be the concentration compound found in all of the extracts analysed. In contrast, Hertog et al. (1992) reported that quercetin is the major flavonol found in vegetables such as broccoli, kale, French beans, celery, onions and cranberries. In addition, rutin was found to be the least abundant flavonoid in all the samples tested.

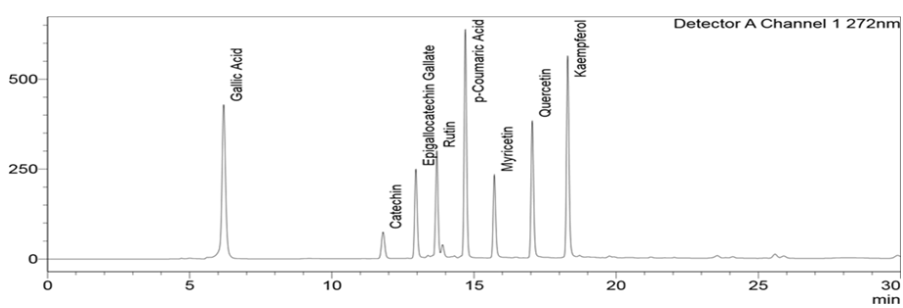

Figure 1. The mixed standards of the HPLC chromatogram
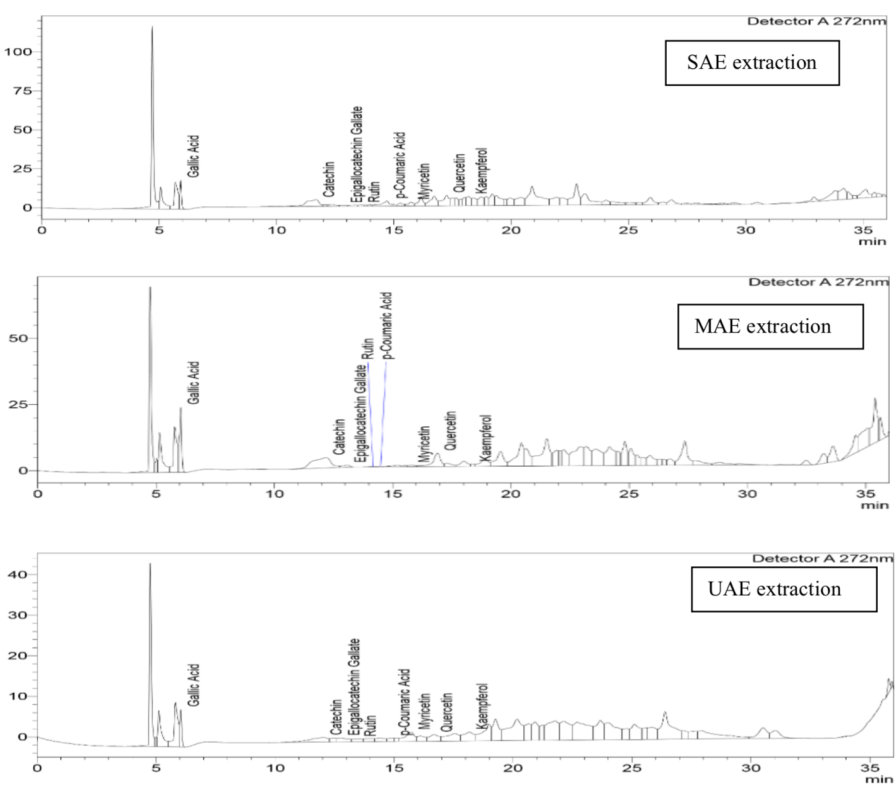

Figure 2. HPLC chromatogram of the M. koenigii leaves extracted using SAE, MAE and UAE

Table 2. The concentration of individual flavonoid in M. koenigii leaves extracted using different extraction techniques (SAE, MAE and UAE)

\begin{tabular}{lcccccccc}
\hline & \multicolumn{7}{c}{ The concentration of the individual flavonoids in every sample (mg/L) } \\
\cline { 2 - 8 } & Gallic acid & Catechin & Epigallocatechin & Rutin & p-coumaric & Myricetin & Quercetin & Kaempferol \\
\hline SAE & $0.16 \pm 0.01^{\mathrm{b}}$ & $1.82 \pm 0.05^{\mathrm{b}}$ & $0.10 \pm 0.01^{\mathrm{b}}$ & $0.05 \pm 0.00^{\mathrm{a}}$ & $0.19 \pm 0.02^{\mathrm{a}}$ & $0.31 \pm 0.01^{\mathrm{b}}$ & $0.50 \pm 0.02^{\mathrm{a}}$ & $0.15 \pm 0.01^{\mathrm{a}}$ \\
$\mathrm{MAE}$ & $0.27 \pm 0.01^{\mathrm{a}}$ & $2.29 \pm 0.02^{\mathrm{a}}$ & $0.85 \pm 0.06^{\mathrm{a}}$ & $0.06 \pm 0.01^{\mathrm{a}}$ & $0.01 \pm 0.00^{\mathrm{c}}$ & $0.46 \pm 0.03^{\mathrm{a}}$ & $0.30 \pm 0.02^{\mathrm{b}}$ & $0.17 \pm 0.01^{\mathrm{a}}$ \\
$\mathrm{UAE}$ & $0.18 \pm 0.01^{\mathrm{b}}$ & $0.83 \pm 0.05^{\mathrm{c}}$ & $0.23 \pm 0.01^{\mathrm{b}}$ & $0.07 \pm 0.01^{\mathrm{a}}$ & $0.07 \pm 0.00^{\mathrm{b}}$ & $0.13 \pm 0.01^{\mathrm{c}}$ & $0.22 \pm 0.02^{\mathrm{b}}$ & $0.11 \pm 0.00^{\mathrm{a}}$ \\
\hline
\end{tabular}

Solvent-assisted $=$ SAE, Microwave assisted $=$ MAE, Ultrasonic assisted $=$ UAE. Values represent the mean \pm standard deviation. Values with the same letter superscript are not significantly different $(\mathrm{P}<0.05)$ between samples within rows. 
The different results obtained from the different extraction procedures observed between flavonoids could arise from the different properties embedded within each type of flavonoid (Mohd Zainol et al., 2009).

\section{Conclusion}

M. koenigii leaves extracted using UAE exhibited better antioxidant activity than that of MAE and SAE. The analyses of TPC and TFC showed that the MAE extract $M$. koenigii leaves showed the best results compared to the UAE and the SAE. M. koenigii leaves extracted by MAE exhibited the highest total number of individual flavonoids compared to $M$. koenigii leaves extracted using UAE and SAE had the highest concentration of p-coumaric acid, myricetin and quercetin concentration $(\mathrm{mg} / \mathrm{L})$. Catechin was the highest flavonoid detected in all the different extraction methods used in the study. The main strength of this study is that it narrows the current discrepancy between the impacts of different extraction methods on the antioxidant properties of M. koenigii.

\section{Conflict of interest}

The authors declare that there is no conflict of interest in the conduct of this study.

\section{Acknowledgement}

This research was supported by a grant (NRGS/53131) from the research council of Universiti Malaysia Terengganu. The authors would like to thank UMT'S Centre of Research and Field Service, and Faculty of Fisheries and Food Sciences for the facilities provided for the study.

\section{References}

AOAC International. (2007). Official Methods of Analysis of AOAC International. AOAC Official Method 990.26. 17th ed. Gaithersburg, MD. USA: AOAC International.

Azizah, O., Mukhtar, N.J., Ismail, N.S. and Chang, S.K. (2014). Phenolics, flavonoids content and antioxidant activities of 4 Malaysian herbal plants. International Food Research Journal, 21(2), 759766.

Bak, M.-J., Ok, S., Jun, M. and Jeong, W.-S. (2012). 6Shogaol-rich extract from ginger up-regulates the antioxidant defence systems in cells and mice. Molecules, 17(7), 8037-8055. https:// doi.org/10.3390/molecules17078037.

Bouaoudia-Madi, N., Boulekbache-Makhlouf, L., Madani, K., Silva, A.M.S., Dairi, S., Oukhmanou-
Bensidhoum, S. and Cardoso, S.M. (2019). Optimization of ultrasound-assisted extraction of polyphenols from Myrtus communis L. Pericarp. Antioxidants, 8(7), 205. https://doi.org/10.3390/ antiox 8070205 .

Chong, K.H., Majid, N.I., Mohd Zainol, M.K., Mohamad, H. and Mohd Zin, Z. (2018). Preliminary phytochemical screening and effect of hot water extraction conditions on phenolic contents and antioxidant capacities of Morinda citrifolia leaf. Malaysian Applied Biology, 47(4), 13-24.

Dahmoune, F., Nayak, B., Moussi, K., Remini, H. and Madani, K. (2015). Optimization of microwaveassisted extraction of polyphenols from Myrtus communis L. leaves. Food Chemistry, 166, 585-595. https://doi.org/10.1016/j.foodchem.2014.06.066

Dharmaraja, A.T. (2017). Role of reactive oxygen species (ROS) in therapeutics and drug resistance in cancer and bacteria. Journal of Medicinal Chemistry, 60(8), 3221-3240. https://doi.org/10.1021/ acs.jmedchem.6b01243

Dineshkumar, B., Mitra, A. and Mahadevappa, M. (2010). Antidiabetic and hypolipidemic effects mahanimbine carbazole alkaloid from Muraya koenigii Rutaceae leaves. International Journal of Phytomedicine, 6(2), 22- 30.

Ghasemzadeh, A., Jaafar, H.Z.E., Rahmat, A. and Devarajan, T. (2014). Evaluation of bioactive compounds, pharmaceutical quality, and anticancer activity of curry leaf (Murraya koenigii L.). Evidence -Based Complementary and Alternative Medicine, 2014, 873803. https://doi.org/10.1155/2014/873803

Hertog, M.G.L., Hollman, P.C.H. and Venema, D.P. (1992). Optimization of a quantitative HPLC determination of potentially anticarcinogenic flavonoids in vegetables and fruits. Journal of Agriculture and Food Chemistry, 40(9), 1591-1598. https://doi.org/10.1021/jf00021a023.

Ince, A.E., Sahin, S. and Sumnu, G. (2012). Comparison of microwave and ultrasound-assisted extraction techniques for leaching of phenolic compounds from nettle. Journal of Food Science and Technology, 51 (10), 2776-2782. https://doi.org/10.1007/s13197-012 -0828-3.

Jun, X., Deji, S., Ye, L. and Rui, Z. (2011). Comparison of in vitro antioxidant activities and bioactive components of green tea extracts by different extraction methods. International Journal of Pharmaceutics, 408(1-2), 97-101. https:// doi.org/10.1016/j.ijpharm.2011.02.002.

Jahromi, S.G. (2019). Extraction techniques of phenolic compounds from plants. In Soto-Hernandez, M. (Ed.) Plant physiological aspects of phenolic 
compounds. IntechOpen E-Book. https:// doi.org/10.5772/intechopen.84705.

Jain, V., Monim, M. and Laddha K. (2012). Murraya koenigii: An update review. International Journal of Ayurvedic and Herbal Medicine 2(4), 607-627.

Jacotet-Navarro, M., Rombaut, N., Deslis, S., FabianoTixier, A.-S., Pierre, F.-X., Bily, A. and Chemat, F. (2016). Towards a "dry" bio-refinery without solvents or added water using microwaves and ultrasound for total valorization of fruit and vegetable by-products. Green Chemistry, 18(10), 3106-3115. https://doi.org/10.1039/C5GC02542G.

Ledesma-Escobar, C.A., Priego-Capote, F. and Luque de Castro, M.D. (2015). Comparative study of the effect of auxiliary energies on the extraction of Citrus fruit components. Talanta, 144, 522-528. https:// doi.org/10.1016/j.talanta.2015.07.011

Luque-García, J. and Luque de Castro, M. (2003). Ultrasound: a powerful tool for leaching. $\operatorname{Tr} A C$ Trends in Analytical Chemistry, 22(1), 41-47. https://doi.org/10.1016/s0165-9936(03)00102-x

Malik, N.H., Mohd Zin, Z., Abd Razak, S.B., Ibrahim, K. and Zainol, M.K. (2017). Antioxidant activity and flavonoids contents in leaves of selected Mangrove species in Setiu Wetland. Journal of Sustainability Science and Management, 3, 24-34.

Mamat, H., Akanda, J.M.H., Zainol, M.K. and Yu, A.I. (2018). The influence of seaweed composite flour on the physicochemical properties of muffin. Journal of Aquatic Food Product Technology, 27(5), 635-642, https://doi.org/10.1080/10498850.2018.1468841.

Medina-Torres, N., Ayora-Talavera, T., EspinosaAndrews, H., Sánchez-Contreras, A. and Pacheco, N. (2017). Ultrasound assisted extraction for the recovery of phenolic compounds from vegetable sources. Agronomy, 7(3), 47. https://doi.org/10.3390/ agronomy 7030047

Mohd Zainol, M.M., Abdul-Hamid, A., Bakar, F.A. and Dek, S.P. (2009). Effect of different drying methods on the degradation of selected flavonoids in Centella asiatica. International Food Research Journal, 16 (4), 531-537.

Moniruzzaman, M., Yung An, C., Rao, P.V., Hawlader, M.N.I., Azlan, S.A.B.M., Sulaiman, S.A. and Gan, S.H. (2014). Identification of phenolic acids and flavonoids in monofloral honey from Bangladesh by high performance liquid chromatography: Determination of antioxidant capacity. BioMed Research International, 2014, 737490. https:// doi.org/10.1155/2014/737490.

Ng, K.S., Mohd Zin, Z., Mohd Maidin, N. and Zainol, M.K. (2020). The ramification of fermentation time on antioxidant properties of Napier grass herbal tea by black tea processing method. Food Research, 4 (2), 349-357. https://doi.org/10.26656/fr.2017.4 (2). 265

Nouha, M., Ioannou, I., Paris, C., Mohamed, G. and Nourhene, B. (2017). Antioxidants of Maltease orange peel: comparative investigation of the efficiency of four extraction methods. Journal of Applied Pharmaceutical Science, 7(11), 126-135. https://doi.org/10.7324/JAPS.2017.71119

Routray, W. and Orsat, V. (2012). MAE of phenolic compounds from blueberry leaves and comparison with other extraction methods. Industrial Crops and Products, 58, 36-45. https://doi.org/10.1016/ j.indcrop.2014.03.038

Seal, T. (2016). Quantitative HPLC analysis of phenolic acids, flavonoids and ascorbic acid in four different solvent extracts of two wild edible leaves, Sonchus arvensis and Oenanthe linearis of North-Eastern region in India. Journal of Applied Pharmaceutical Science, 6(2), 157-166, https://doi.org/10.7324/ JAPS.2016.60225.

Sepahpour, S., Selamat, J., Abdul Manap, M., Khatib, A. and Abdull Razis, A. (2018). Comparative analysis of chemical composition, antioxidant activity and quantitative characterization of some phenolic compounds in selected herbs and spices in different solvent extraction systems. Molecules, 23(2), 402. https://doi.org/10.3390/molecules23020402.

Singh, S., More, P.K. and Mohan, S.M. (2014). Curry leaves (Murraya koenigii Linn. Sprengal) -a miracle plant. Indian Journal of Scientific Research, 4(1), 46 $-52$

Sinha, P., Javed, A., Neha, B., Honey, J. and Anuj, B. (2012). Curry leaf: A Medical Herb. Asian Journal of Pharmaceutical Research, 2, 51-53.

Tiwari, B.K. (2015). Ultrasound: A clean, green extraction technology. TrAC Trends in Analytical Chemistry, 71, 100-109. https://doi.org/10.1016/ j.trac.2015.04.013.

Zainol, M.K., Abd-Hamid, A., Yusof, S. and Muse, R. (2003). Antioxidative activity and total phenolic compounds of leaf, root and petiole of four accessions of Centella asiatica (L.) Urban. Food Chemistry, 81(4), 575-581. https://doi.org/10.1016/ S0308-8146(02)00498-3

Zainol, M.K., Wong, K.Y., Mohd Zin, Z., Kamarudin, K.S., Danish-Daniel, M. and Mamat, H. (2018). Effect of ethanol concentration in ultrasonic assisted extraction technique on antioxidative properties of passion fruit (Passiflora edulis) leaves. Malaysian Applied Biology, 47(6), 19-27. 